\title{
Ampirik Kip Ayrıştırma Yöntemi ile Elde Edilen İçsel Kip Fonksiyonlarının Derin Öğrenme Tabanlı Rüzgâr Hızı Tahmin Modeli Başarımına Etkisinin Belirlenmesi
}

\author{
Caner Barış ${ }^{1}$, Ahmed Cemil Bilgin ${ }^{2}$, Aytaç Altan ${ }^{3 *}$ \\ ${ }^{1}$ Zonguldak Bülent Ecevit Üniversitesi, Fen Bilimleri Enstitüsü, Elektrik Elektronik Mühendisliği Anabilim Dalı, Zonguldak, Türkiye \\ (ORCID: 0000-0003-0869-2788), caner.baris@,fbe.karaelmas.edu.tr \\ ${ }^{2}$ Zonguldak Bülent Ecevit Üniversitesi, Fen Bilimleri Enstitüsü, Elektrik Elektronik Mühendisliği Anabilim Dalı, Zonguldak, Türkiye \\ (ORCID: 0000-0001-7819-8940), ahmedc.bilgin@,fbe.karaelmas.edu.tr \\ $3^{*}$ Zonguldak Bülent Ecevit Üniversitesi, Mühendislik Fakültesi, Elektrik Elektronik Mühendisliği Bölümü, Zonguldak, Türkiye \\ (ORCID: 0000-0001-7923-4528), aytacaltan@beun.edu.tr
}

(İlk Geliş Tarihi 21 Kasım 2021 ve Kabul Tarihi 25 Aralık 2021)

(DOI: 10.31590/ejosat.1026742)

\begin{abstract}
ATIF/REFERENCE: Barış, C., Bilgin, A. C., \& Altan, A. (2021). Ampirik Kip Ayrıştırma Yöntemi ile Elde Edilen İçsel Kip Fonksiyonlarının Derin Öğrenme Tabanlı Rüzgâr Hızı Tahmin Modeli Başarımına Etkisinin Belirlenmesi. Avrupa Bilim ve Teknoloji Dergisi, (31), 661-669.

\section{$\ddot{O} \mathbf{z}$}

Son yıllarda küresel anlamda etkisini yoğun şekilde gösteren iklim değişikliğinin temelinde fosil yakıt tüketimi kaynaklı sera etkisinin kuvvetlenmesinin yer aldığı bilinmektedir. İklim değişikliği neticesinde canlılar için hayati önem taşıyan su kaynaklarının azalacağı, ekolojik dengenin bozularak çölleşme ve kuraklığın artacağı öngörülmektedir. Bu sorunla başa çıkılabilmesi için fosil yakıt tüketiminin azaltılması ve enerji ihtiyacının yenilenebilir enerji kaynakları ile karşılanması gerekmektedir. Bu nedenle, temiz ve yenilenebilir bir enerji türü olan rüzgâr enerjisine olan ilgi dünya çapında her geçen gün artmaktadır. Bununla birlikte, rüzgâr hızının güçlü rastgeleliği ve durağan olmaması rüzgâr gücünün elektrik şebekesine entegre edilmesini zorlaştırmaktadır. Bu zorlukların üstesinden gelebilmek için rüzgâr hızının güvenilir ve yüksek doğrulukla tahmin edilmesi kritik önem arz etmektedir. Bu çalışmada, doğrusal olmayan dinamiklere sahip rüzgâr hızının yüksek doğrulukla tahmin edilebilmesi için ampirik kip ayrıştırma ve derin öğrenme yöntemlerinden uzun-kısa süreli bellek tekniklerini içeren melez modeldeki içsel kip fonksiyonlarının rüzgâr hızı tahmin performansı üzerindeki etkileri incelenmektedir. Türkiye'nin en yüksek rüzgâr enerji potansiyeline sahip bölgeleri arasında yer alan Marmara bölgesindeki Bandırma meteoroloji istasyonundan toplanan rüzgâr hızı verileri ampirik kip ayrıştırma tekniği ile içsel kip fonksiyonlarına ayrıştırılmaktadır. Her bir içsel kip fonksiyonunun tahmin modeli üzerindeki başarımının belirlenebilmesi için sırasıyla her bir içsel kip fonksiyonu derin öğrenme modeline dahil edilmeden tahmin modellerinin performansları ölçülmektedir. Tahmin modellerinin başarımları istatistiksel performans metriklerine göre hesaplanmaktadır.
\end{abstract}

Anahtar Kelimeler: Ampirik kip ayrıştırma, İçsel kip fonksiyonu, Rüzgâr hızı tahmini, Derin öğrenme, Uzun-kısa süreli bellek.

\section{Determining the Effect of Intrinsic Mode Functions Obtained by the Empirical Mode Decomposition on the Performance of Deep Learning based Wind Speed Prediction Model}

\begin{abstract}
In recent years, it is known that the strengthening of the greenhouse effect caused by fossil fuel consumption is at the root of climate change, which has had an intense impact on the global scale. As a result of climate change, it is predicted that water resources, which are vital for living things, will decrease, and the ecological balance will deteriorate and desertification and drought will increase. In order to cope with this problem, fossil fuel consumption should be reduced and energy needs should be met with renewable energy sources. Therefore, the interest in wind energy, which is a clean and renewable energy type, is increasing day by day around the world. However, the strong randomness and non-stationarity of the wind speed make it difficult to integrate wind power into the electricity
\end{abstract}

* Sorumlu Yazar: aytacaltan@beun.edu.tr 
grid. To overcome these challenges, reliable and highly accurate estimation of wind speed is critical. In this study, the effects of intrinsic mode functions in the hybrid model, which includes empirical mode decomposition and long-short-term memory (LSTM) techniques, on wind speed prediction performance are investigated for high accuracy prediction of wind speed, which has nonlinear dynamics. Wind speed data collected from Bandirma meteorology station in the Marmara region, which is among the regions with the highest wind energy potential in Turkey, are decomposed to intrinsic mode functions by empirical mode decomposition technique. To determine the performance of each intrinsic mode function on the wind speed prediction model, the performances of the prediction models are measured without including each intrinsic mode function in the deep learning model, respectively. The performance of prediction models is computed according to statistical performance metrics.

Keywords: Empirical mode decomposition, Intrinsic mode function, Wind speed prediction, Deep learning, Long-short term memory (LSTM).

\section{Giriş}

Son on y1lda dünyada etkisini yoğun biçimde hissettiren iklim değişikliği ile başa çıkılabilmesi için fosil yakıt tüketiminin azaltılması ve enerji ihtiyacının yenilenebilir enerji kaynakları ile karşılanması kaçınılmaz hale gelmiştir (Zhang et al. 2019). Fosil yakıtlara kıyasla temiz bir enerji kaynağı olan rüzgâr enerjisi tüm yenilenebilir enerji üretim kaynaklarının \%38'ini oluşturmakta olup bu oranın 2021 yılı sonunda \%41'e ulaşması beklenmektedir (Statistical Review of World Energy 2021, U.S. Energy Information Administration). Küresel kurulu kapasitesi 2020 yılında 733,3 GW'a ulaşan rüzgâr enerjisinin kayda değer faydalarına rağmen, rüzgâr enerjisi üretimi hala oynaklık, güçlü rastgelelilik ve kesinti ile temsil edilen ve şebeke işletimi üzerinde sağlıksız bir etkiye neden olabilecek zorlu sorunlarla karşı karşıyadır (Chen et al. 2019). Rüzgâr enerjisi üretiminin rüzgâr hızının stokastik yapısı ve iç kararsızlığından etkilendiği bilinmektedir. Bu zorlukların üstesinden gelinebilmesi için rüzgâr enerjisi kullanımı sürecinde rüzgâr hızının yüksek doğrulukla tahmini büyük önem taşımaktadır (Altan et al. 2021).

Rüzgâr hızı tahmininde fiziksel, uzaysal-zamansal korelasyon, istatistiksel ve makine öğrenmesi gibi tekli modeller kullanılabildiği gibi sinyal işleme/ayrıștırma ve tekli/çoklu optimizasyon tekniklerini içeren melez modeller de kullanılabilmektedir (Altan et al. 2021; Hoolohan et al. 2018; Yu et al. 2018; Ma et al. 2020). Atmosferdeki fiziksel süreçlere dayalı olarak rüzgâr hızını tahmin eden fiziksel modeller genellikle bir yığın meteorolojik ve coğrafi parametreye ihtiyaç duyarlar. Bu modeller, uzun vadeli tahminler için iyi bir performans göstermelerine rağmen bilgi gecikmesi nedeniyle kısa vadeli tahminlerde tatmin edici bir performans sergileyemezler (Liu et al. 2012). Uzaysal-zamansal korelasyon modelleri, farklı bölgelerdeki rüzgâr hıları arasındaki çapraz korelasyonları modelleyerek rüzgâr hızını tahmin ederler (Zhao et al. 018). Doğrusal ve doğrusal olmayan teknikleri içeren istatistiksel modeller, geçmiş rüzgâr hızı verilerini kullanarak rüzgâr hızını tahmin etmektedirler ve fiziksel modellere kıyasla kısa vadeli rüzgâr hızı tahmin problemleriyle uğraşmada daha iyi performans sergilemektedirler. İstatistiksel modeller basit ve etkili olmalarına rağmen zaman serilerinin durağan ve doğrusal özellikleri varsayımı altında oluşturulduğundan, doğrusal olmayan ve durağan olmayan rüzgâr hızı zaman serileri üzerinde sınırlı etkiye sahiptirler (Liu et al. 2021). Otoregresif (autoregressive-AR), otoregresif hareketli ortalama (autoregressive moving averageARMA), otoregresif bütünleşik hareketli ortalama (autoregressive integrated moving average-ARIMA), Kalman filtreleme ve doğrusal regresyon gibi doğrusal teknikler ile doğrusal olmayan otoregresif (nonlinear autoregressive-NAR) ve doğrusal olmayan otoregresif dış kaynaklı (nonlinear autoregressive exogenous-NARX) gibi doğrusal olmayan teknikler istatistiksel modeller içerisinde kullanılmaktadır (Cadenas et al. 2016; Gauterin et al. 2016; Karasu et al. 2017a; Karasu et al. 2017b). Rüzgâr hızındaki oynaklık, durağan olmama, doğrusal olmayanlık, güçlü rastgelelilik ve belirsizlik gibi içsel dinamikler bu modellerin rüzgâr hızını yüksek doğrulukla tahmin etme performansını sinırlandırmaktadır. $\mathrm{Bu}$ zorluğun üstesinden gelebilmek için sinyal ayrıştırma ve optimizasyon teknikleri ile birlikte makine öğrenmesi ve yapay zekâ yöntemlerini içeren melez modeller geliştirilmektedir (Altan et al. 2021).

Melez modeller içerisinde kullanılan sinyal ayrıştırma teknikleri ile orjinal rüzgâr hızı zaman serileri alt serilere ayrılarak tahmine dayalı özellikler çıkarılmakta ve kararsızlık azaltılmaktadır (Liu and Chen 2019; Ma et al. 2017). Rüzgâr hızı tahmini için oluşturulan melez modeller içerisinde genellikle ampirik kip ayrıştırma (empirical mode decomposition-EMD), topluluk ampirik kip ayrıştırma (ensemble empirical mode decomposition-EEMD), komple topluluk ampirik kip ayrıştırma (complete ensemble empirical mode decomposition with adaptive noise-CEEMDAN), hızlı topluluk ampirik kip ayrıştıma (fast ensemble empirical mode decomposition-FEEMD), ampirik dalgacık dönüşümü (empirical wavelet transform-EWT), dalgacık paketi ayrıştırma (wavelet packet decomposition-WPD), tekil spektrum analizi (singular spectrum analysis-SSA) ve varyasyonel kip ayriştırma (variational mode decompositionVMD) teknikleri kullanılmaktadır. Genellikle makine öğrenmesi ve derin öğrenme tabanlı melez model yapısında kullanılan sinyal ayrıştırma yöntemleri rüzgâr hızı tahmin performansının iyileştirilmesine büyük katkı sağlamaktadırlar (Altan et al. 2021; Ruiz-Aguilar et al. 2021; Chen et al. 2021; Altan and Karasu 2021; Yan et al. 2020). Bununla birikte, melez model yapısında kullanılan ayrıştırma tekniklerinin tahmin modelinin hesaplama karmaşıklığını arttırdığı bilinmektedir (Liu et al. 2019). Hesaplama verimliliği ve tahmin doğruluğu göz önüne alındığında rüzgâr hızı tahmini için oluşturulan melez model yapısında kullanılan ayrıştırma yöntemi ile elde edilen her bir alt bandın modelin tahmin performansı üzerindeki etkisinin bilinmesi önem taşımaktadır.

Bu çalışmada, rüzgâr hızının oynaklık, güçlü rastgelelilik, durağan olmama ve belirsizlik gibi doğrusal olmayan davranışları ile başa çıkabilmek için ampirik kip ayrıştırma ve yapay zekâ temelli uzun-kısa süreli bellek (long-short-term memory-LSTM) yöntemlerini içeren melez tahmin modelindeki içsel kip fonksiyonlarının (intrinsic mode functions-IMFs) rüzgâr hızı tahmin performansı üzerindeki etkileri incelenmektedir. Çalışmanın geri kalanı aşağıdaki şekilde organize edilmiştir. Rüzgâr hızı tahmini için oluşturulan tahmin modelinin çerçevesi ikinci bölümde verilmektedir. Üçüncü bölümde, her bir IMF ile elde edilen tahmin modellerinin deneysel sonuçları sunulmakta ve tartışılmaktadır. Son bölümde, çalışmanın sonuçları ve gelecek projeksiyonu vurgulanmaktadır. 


\section{Rüzgâr Hızı Tahmin Modeli}

$\mathrm{Bu}$ bölümde, çalışmada ele alınan EMD tekniği ile elde edilen her bir IMF'nin derin öğrenme tabanlı melez rüzgâr hızı tahmin modeli performansına etkisinin incelenebilmesi için sırasıyla her bir IMF'nin derin öğrenme modeline dahil edilmediği rüzgâr hızı tahmin modellerinin oluşturulma çerçevesi anlatılmaktadır. Ayrıca, elde edilen tahmin modellerinin performanslarının kıyaslanabilmesi için tekli LSTM ve tüm IMF'lerin dahil edildiği EMD-LSTM tahmin modelleri açıklanmaktadır.

\subsection{Ampirik Kip Ayrıştırma}

Huang ve arkadaşları tarafından geliştirilen EMD yönteminin temel fikri durağan olmayan sinyali, sinyal durağan olana kadar elemek için Hilbert-Huang dönüşümünü kullanmaktır (Huang et al. 1998). Bu yöntemin temelinde, karmaşıklık durumuna bağlı olarak sinyallerin aynı anda birden fazla farklı eş zamanlı salınım kiplerine sahip olabileceği düşüncesi yer almaktadır. Bu düşünceden yola çıkılarak karmaşık bir sinyal nispeten durağan alt seriler olan ve kolayca modellenebilen birkaç IMF ve bir kalıntının toplamına ayrıştırılabilmektedir. Burada, IMF'ler karmaşık sinyallerin yerel karakteristik ölçeğine dayanılarak çıkarılmaktadır. EMD'de bir fonksiyon aşağıdaki iki koşulu sağlıyor ise IMF olarak tanımlanmaktadır. Bu koşullar;

- tüm veri kümesinde, ekstremumların toplamı ve sıfır geçişlerin toplamı eşit olmalı veya en fazla bir farklılık göstermelidir;

- yerel maksimum ve minimumlarla tanımlanan zarfin ortalaması herhangi bir noktada sıfır olmalıdır (Chen et al. 2012).

Belirtilen bu iki koşul bir IMF'nin hemen hemen periyodik bir fonksiyon olmasını ve ortalamanın sifira ayarlanmasını sağlamaktadır. Belirli bir orijinal rüzgâr hızı zaman serisi olarak bir $y(t)$ sinyali verildiğinde, EMD algoritması aşağıdaki gibi tanımlanabilir:

$$
y(t)=\sum_{j=1}^{m} f_{j}(t)+R_{m}(t)
$$

burada, $f_{j}(t)(j=1,2, \ldots, m)$ farklı IMF'leri temsil etmektedir. $R_{m}(t), m$ 'ninci IMF'nin türetilmesinden sonraki kalıntıyı ifade etmektedir. Her bir IMF'nin çıkarılma süreci şu şekilde açıklanabilir:

(i) Orijinal rüzgâr hızı zaman serisi $y(t)$ 'nin tüm ekstremumları tanımlanır.

(ii) Bir kübik spline çizgisi kullanılarak tüm yerel maksimumları birleştirerek türetilebilen üst $\left\{y_{u}(t)\right\}$ ve alt $\left\{y_{l}(t)\right\}$ zarflar hesaplanır.

(iii) Elde edilen üst ve alt zarflar yardımıyla ortalama zarf $m(t)=\left(y_{u}(t)+y_{l}(t)\right) / 2$ hesaplanir.

(iv) Orijinal rüzgâr hızı zaman serisi $y(t)$ ortalama zarf serisinden çıkarılır ve $d(t)=y(t)-m(t)$ olarak tanımlanır.

(v) $d(t)$ 'nin özellikleri test edilir:

- $d(t)$ bir IMF ise, o zaman $f(t)=d(t)$ ayarlanır. $d(t)$ $i$ 'ninci IMF olarak belirlenir. $\mathrm{Bu}$ arada $y(t)$ değeri kalıntı $R(t)=y(t)-f(t)$ ile değiştirilir.

- $d(t)$ bir IMF değil ise; $y(t), d(t)$ ile değiştirilir. (vi) $R(t)$, durma şartlarını yerine getirene kadar (i)-(v) adımları tekrarlanır (Huang et al. 2003).

\subsection{Uzun-Kısa Süreli Bellek}

Tekrarlayan sinir ağı (recurrent neural network-RNN), giriş dizilerini alarak iç döngüler yoluyla sıralı kalıpları öğrenen bir ağdır. A ̆g yapısında, ağırlıkların öğrenilmesi için geri yayılım yapılır ve zincir kuralı ile hesaplanan eğimin yayılması sağlanır. Değerler, sigmoid ve tanh fonksiyonları gibi aktivasyon fonksiyonuna geri yayıldığında, eğim aşırı derecede küçük (veya aşırı büyük) hale gelir ve kaybolma (veya gradyanların patlaması) problemiyle karşılaşır. Geri yayılım, uzun menzilli bağımlılığa karşı savunmasızdır. Bu sorunların üstesinden gelinebilmesi için geliştirilen LSTM modelleri uzun ve kısa vadeli bağımlılık problemlerini çözmede istikrarlı ve güçlü bir yeteneğe sahiptir. LSTM ağı sadece bitişik geçici bilgileri tutmakla kalmaz aynı zamanda uzun vadeli bilgileri de kontrol eder (Hochreiter and Schmidhuber 1997). LSTM ağı mimarisi Şekil 1'de gösterilmektedir.

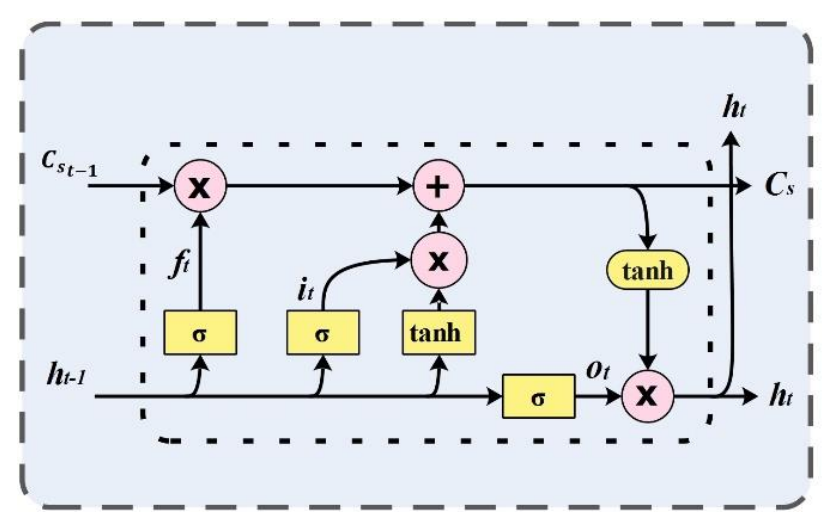

Şekil 1. LSTM ă̆ mimarisi.

LSTM'ler nöronlar yerine bellek bloklarından oluşmaktadır. Bir LSTM ağında, bir bellek hücresi ile birlikte giriş, çıkış ve unutma kapıları bulunmaktadır. LSTM ağı bu kapılar yardımıyla hücre durumuna bilgi ekleyebilmekte veya çıkarabilmektedir. Bellek hücresi LSTM ağının çekirdeği olarak tanımlanmaktadır.

Giriş verileri giriş kapısının çıkışı ile çarpılarak hücreye biriktirilebilecek yeni bilgiler tanımlanmaktadır. Ağa yayılan biligiler ağın çıkış verisi ile çıkış geçidinin aktivasyonu ile çarpılarak hesaplanmaktadır. Önceki zamanın hücre durumları, unutma geçidinin aktivasyonu ile çarpılarak hücrenin son durumunun unutulup unutulmayacağı belirlenmektedir. Hücre durumunun güncellenmesi ve LSTM ağı çıktısının hesaplanma prosedürü aşağıdaki işlem adımları takip edilerek gerçekleştirilmektedir (Sainath et al. 2015):

- hücre durumundan hangi bilgilerin atılacağına karar verme aşaması:

$x_{t}$ ve $h_{t-1}$ değeri alınır ve bir sigmoid fonksiyon

$$
f_{t}=\sigma\left(w_{f} \cdot\left[h_{t-1}, x_{t}\right]+b_{f}\right)
$$

aracılığıyla atılıp atılmayacağı tanımlanır. Burada, $x_{t}$ girişi ve $h_{t-1}$ gizli durumu temsil etmektedir.

- hangi yeni bilginin hücre durumunda depolanacağını belirleme aşaması:

Hücre durumunda hangi bilgilerin depolanacağına bir sigmoid katman tarafindan karar verilir. $x_{t}$ ve $h_{t-1}$ tarafindan $\tanh (\cdot)$ 663 
katmanından elde edilen değerler yeni bir aday değer $\left\{\tilde{C}_{t}\right\}$ olarak tanımlanır.

$$
\begin{aligned}
& i_{t}=\sigma\left(w_{i} \cdot\left[h_{t-1}, x_{t}\right]+b_{i}\right) \\
& \tilde{C}_{t}=\tanh \left(w_{C} \cdot\left[h_{t-1}, x_{t}\right]+b_{C}\right)
\end{aligned}
$$

- önceki hücre durumu $C_{t-1}$ 'yi yeni hücre durumu $C_{t}$ 'ye güncelleme aşaması:

Unutmaya karar verilen bilgileri unutulabilmesi için $C_{t-1}$ hücre durumu $f_{t}$ ile çarpılır. Daha sonra, yeni bir hücre durumu elde etmek için, $i_{t}$ ile $\tilde{C}_{t}$ çarpılır ve elde edilen terim önceki terime eklenerek yeni hücre durumu $\left\{C_{t}\right\}$ belirlenir.

$$
C_{t}=f_{t} \times C_{t-1}+i_{t} \times \tilde{C}_{t}
$$

\section{- hangi bilginin çıkış olacağına karar verme aşaması:}

Hangi bilginin hücre durumunda çıkış olacağına bir sigmoid katman tarafindan karar verilir.

$$
\begin{aligned}
& s_{t}=\sigma\left(w_{o} \cdot\left[h_{t-1}, x_{t}\right]+b_{o}\right) \\
& h_{t}=s_{t} \times \tanh \left(C_{t}\right)
\end{aligned}
$$

Burada, $b_{f}, b_{i}, b_{C}, b_{o}$ sapma vektörlerini $w_{f}, w_{i}, w_{C}, w_{o}$ ağırlık matrislerini temsil etmektedir. $\sigma(\cdot)$, kapı aktivasyon fonksiyonu olarak kullanılan lojistik sigmoid fonksiyonudur ve

$$
\sigma(x)=\frac{1}{1+e^{-x}}
$$

ile tanımlanır. $\tanh (\cdot)$, hiperbolik tanjant fonksiyonu olup giriş ve çıkış bloğunun aktivasyon fonksiyonu

$$
\tanh (x)=\frac{e^{x}-e^{-x}}{e^{x}+e^{-x}}
$$

şeklinde ifade edilir.

\section{Deneysel Sonuçlar ve Tartışma}

Bu bölümde, Türkiye'nin en yüksek rüzgâr enerji potansiyeline sahip bölgeleri arasında yer alan Marmara bölgesindeki Bandırma meteoroloji istasyonundan toplanan rüzgâr hızı verileri EMD tekniği ile IMF'lerine ayrıştırılmaktadır. Ayrıştırılan her bir IMF'nin dahil edilmediği toplam $10 \mathrm{melez}$ rüzgâr hızı tahmin modeli oluşturulmaktadır. Elde edilen modellerin performansları hata metriklerine göre ölçülmektedir. Her bir IMF'nin melez model performansı çalışmada bahsedilen tekli ve melez modeller ile kiyaslanmakta ve her bir IMF'nin melez rüzgâr hızı tahmin modeli üzerindeki etkisi araştırılmaktadır.

Çalışmada kullanılan rüzgâr hızı verileri Şekil 2'de gösterilen Türkiye'nin Marmara bölgesindeki Bandırma meteoroloji istasyonundan toplanmıştır. Bu meteoroloji istasyonları bölgedeki diğer ölçüm istasyonlarından izole edilmiştir. İstasyondan 51.725 saatlik rüzgâr hız ölçüm verisi elde edilmiştir (Akçay and Filik 2017). Çalışmada kullanılan veri seti Şekil 2'de gösterilen istasyondan alınan verilerin 10 saatlik ortalaması alınarak elde edilmiştir. Çalışmada kullanılan veri seti 5.173 rüzgâr hızı verisini içermektedir. Veri setindeki en düşük rüzgâr hızı verisi $0,6 \mathrm{~m} / \mathrm{s}$, en yüksek rüzgâr hızı verisi $25,7 \mathrm{~m} / \mathrm{s}$ 'dir. Veri setindeki ortalama rüzgâr hızı 3,99 m/s olup standart sapması 2,51 m/s'dir.

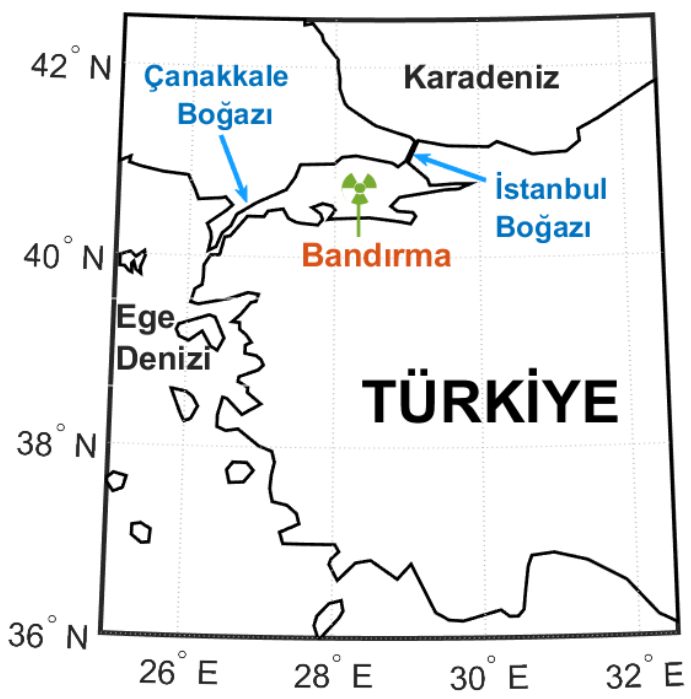

Şekil 2. Veri toplanan rüzgâr istasyonunun konumu.

Çalışmada oluşturulan modellerin performanslarının veriden bağımsız olduğunun gösterilebilmesi için modellerin eğitim, geçerlilik ve test aşamalarında kullanılmak üzere veri seti sırasıly $\% 70$, \%15 ve \%15'lik kısımlara ayrılmıştır. Veri setindeki ilk 3.623 rüzgâr hızı verisi modellerin eğitim aşamasında kullanılmıştır. Sonraki 775 veri ile oluşturulan modellerin geçerliliği test edilmektedir. Oluşturulan modellerin performansları veri setinin sonunda yer alan 775 rüzgâr hızı verisi üzerinde ölçülmüştür. Modellerin performanslarının ölçülmesinde kullanılan test veri setindeki en düşük rüzgâr hızı verisi $0,6 \mathrm{~m} / \mathrm{s}$, en yüksek rüzgâr hızı verisi $11,6 \mathrm{~m} / \mathrm{s}$ 'dir. Test veri setindeki ortalama rüzgâr hızı $3,71 \mathrm{~m} / \mathrm{s}$ olup standart sapmas1 $2,29 \mathrm{~m} / \mathrm{s}^{\prime}$ dir.

Çalışmada oluşturulan modellerin performansının değerlendirilmesinde, literatürde rüzgâr hızı tahmin modellerinin değerlendirilmesinde kullanılan ve Eş. (10-12) ile verilen ortalama mutlak hata (mean absolute error-MAE), ortalama karesel hata (mean squared error-MSE) ve kök ortalama karesel hata (root mean square error-RMSE) hata metrikleri kullanılmıştır. Söz konusu hata metrikleri ile oluşturulan tahmin modellerinin hem doğruluğu hem de güvenilirliği test edilmiştir.

Çalışmadaki melez rüzgâr hızı tahmin modellerinin oluşturulmasında ayrıştırma yöntemi olarak EMD tekniği kullanılmıştır. EMD tekniği ile 5.173 rüzgâr hızı verisinden oluşan veri seti Şekil 3'te görüldüğü gibi 10 IMF'ye ayrıştırılmıştır.

$$
\begin{aligned}
& M A E=\frac{1}{n} \sum_{i=1}^{n}\left|p_{\text {tahmin }}^{i}-p_{\text {gerçek }}^{i}\right| \\
& M S E=\frac{1}{n} \sum_{i=1}^{n}\left(p_{\text {tahmin }}^{i}-p_{\text {gerçek }}^{i}\right)^{2} \\
& R M S E=\sqrt{\frac{1}{n} \sum_{i=1}^{n}\left(p_{\text {tahmin }}^{i}-p_{\text {gerçek }}^{i}\right)^{2}}
\end{aligned}
$$



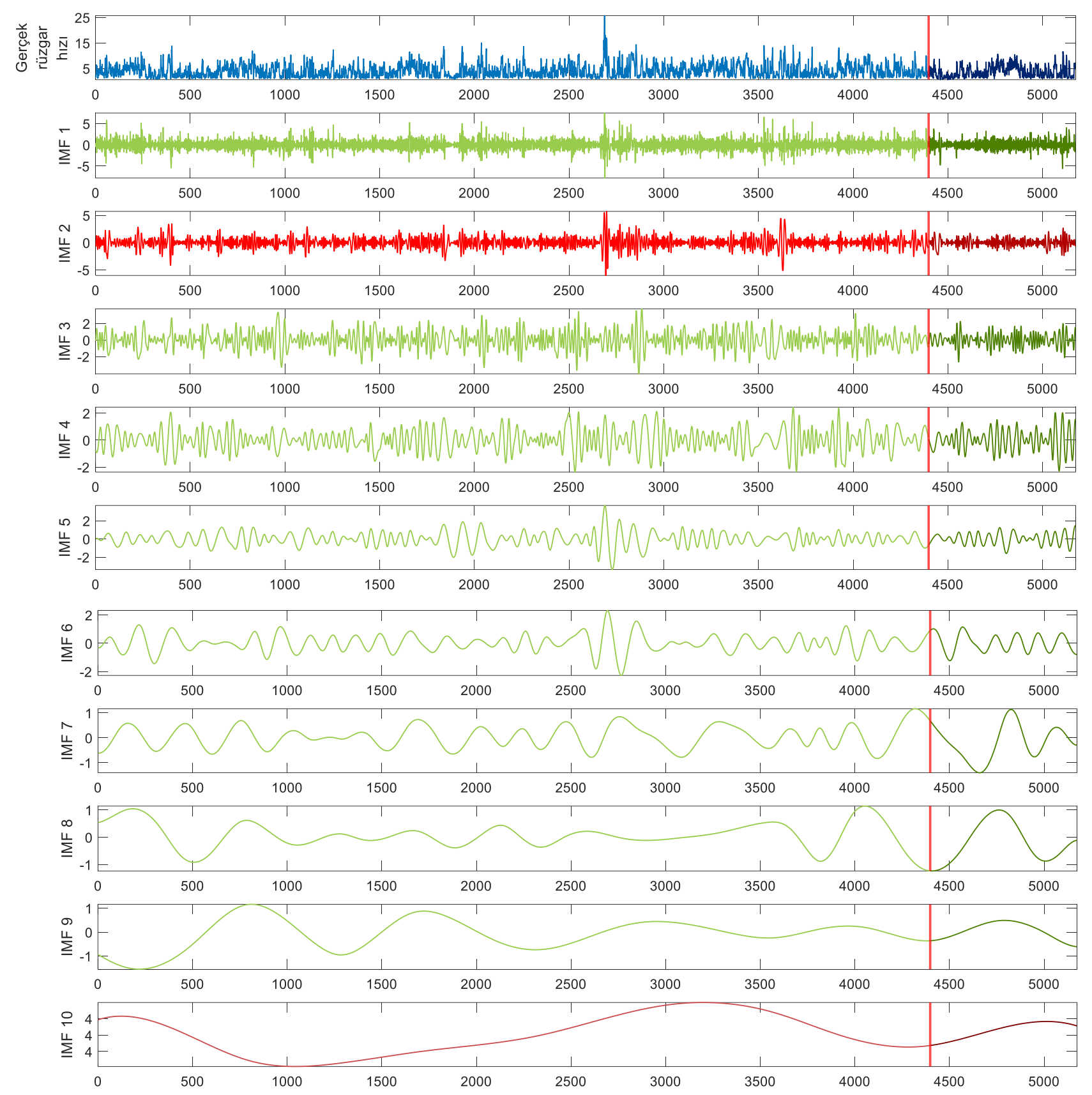

Şekil 3. Bandırma meteoroloji istasyonundan toplanan rüzgâr hızı veri seti için EMD'nin IMF'leri.

Çalışmanın tahmin modeli oluşturma aşamasında derin öğrenme yöntemlerinden LSTM tekniği kullanılarak tekli LSTM rüzgâr hızı tahmin modeli oluşturulmuştur. $\mathrm{Bu}$ tekli modelin oluşturulmasındaki amaç ayrıştırma yönteminin rüzgâr hızı tahmin modeli performansını iyileştirmedeki etkisinin ölçülebilmesidir. Oluşturulan LSTM modelinde, gizli katman sayıs1 200 ve maksimum epok sayısı 150 alınmıştır. Model parametreleri Adam optimizasyon tekniği ile optimize edilmiştir. Şekil 3'te gösterilen gerçek rüzgâr hızı verisi EMD tekniği ile toplam 10 IMF'ye ayrılmıştır. Her bir IMF verisi LSTM modeli için giriş olarak kullanılarak toplam 10 farklı alt LSTM modelleri elde edilmiştir. Bu alt modeller birleştirilerek melez EMD-LSTM rüzgâr hızı tahmin modeli oluşturulmuştur. Çalişmada kullanılan tekli LSTM modelinin MAE, MSE ve RMSE hata metriklerine göre tahmin performans1 surasiyla $1,3844,3,2063$ ve 1,7906 e-ISSN: 2148-2683 olarak ölçülmüştür. Melez EMD-LSTM modelinin tahmin performansı ise MAE, MSE ve RMSE hata metriklerine göre sırasiyla $0,7663,1,1902$ ve 1,0910 olarak belirlenmiştir. Melez EMD-LSTM modelinin tahmin performansı MAE, MSE ve RMSE hata metriklerine göre tekli LSTM modelinin tahmin performansı ile kıyaslandı̆̆ında, melez EMD-LSTM modeli ile MAE, MSE ve RMSE hata metriklerine göre rüzgâr hızı tahmin performansında sirasıyla $\% 80,66, \% 169,39$ ve $\% 64,12$ iyileşme olduğu görülmektedir. Ayrıştırılan her bir IMF'nin tahmin modeli üzerindeki başarımının belirlenebilmesi için her bir IMF'nin dahil edilmediği derin öğrenme tabanlı melez rüzgâr hızı modelleri oluşturulmuştur. Oluşturulan tahmin modellerinin MAE, MSE ve RMSE hata metriklerine göre performansları Tablo 1'de sunulmuştur. Tablo 1 incelendiğinde, IMF10'un dahil edilmediği modelde en yüksek başarım elde edilmiştir. $\mathrm{Bu}$ model tüm 665 
IMF'lerin dahil edildiği melez EMD-LSTM tahmin modeli ile karşılaştırıldığında, rüzgâr hızını MAE, MSE ve RMSE hata metriklerine göre sirasiyla $\% 4,61, \% 10,87$ ve $\% 5,59$ hata ile tahmin ettiği görülmektedir. Çalışmada, IMF2'nin dahil edilmediği model ile en düşük rüzgâr hızı tahmin başarımı elde edilmiştir. Bu modelin tahmin performansı tüm IMF'lerin dahil edildiği melez EMD-LSTM tahmin modelinin performansı ile MAE, MSE ve RMSE hata metriklerine göre karşılaştırıldığında, rüzgâr hızını sırasıyla $\% 55,74, \% 127,10$ ve $\% 50,69$ hata ile tahmin ettiği görülmektedir.

Tablo 1. Çalışmada oluşturulan rüzgâr hızı tahmin modellerinin performanslart.

\begin{tabular}{lllll}
\hline İstasyon & Model & $\boldsymbol{M A E}$ & $\boldsymbol{M S E}$ & $\boldsymbol{R} \boldsymbol{M S E}$ \\
\hline \multirow{3}{*}{ Bandırma } & LSTM & 1.3844 & 3.2063 & 1.7906 \\
& EMD-LSTM & 0.7663 & 1.1902 & 1.0910 \\
& EMD (IMF1 hariç)-LSTM & 0.8941 & 1.3370 & 1.1597 \\
& EMD (IMF2 hariç)-LSTM & $\mathbf{1 . 1 9 3 5}$ & $\mathbf{2 . 7 0 3 0}$ & $\mathbf{1 . 6 4 4 1}$ \\
& EMD (IMF3 hariç)-LSTM & 1.1079 & 2.2629 & 1.5043 \\
& EMD (IMF4 hariç)-LSTM & 1.0549 & 2.1405 & 1.4630 \\
& EMD (IMF5 hariç)-LSTM & 0.9717 & 1.6436 & 1.2820 \\
& EMD (IMF6 hariç)-LSTM & 1.0503 & 2.3338 & 1.5277 \\
& EMD (IMF7 hariç)-LSTM & 1.1680 & 2.5293 & 1.5904 \\
& EMD (IMF9 hariç)-LSTM & 0.8129 & 1.3939 & 1.1806 \\
& EMD (IMF10 hariç)-LSTM & $\mathbf{0 . 8 0 3 4}$ & $\mathbf{1 . 3 3 5 5}$ & $\mathbf{1 . 1 5 5 6}$ \\
\hline
\end{tabular}

Tüm IMF'lerin dahil edildiği melez EMD-LSTM tahmin modelinin eğitim, geçerlilik ve test süreçlerini de içeren regresyon eğrisi Şekil 4 'te sunulmaktadır. Şekil 4 incelendiğinde, bahsedilen modelin rüzgâr hızını \%88,33 doğrulukla tahmin ettiği görülmektedir. Benzer şekilde, IMF10 ve IMF2'nin dahil edilmediği melez modellerin eğitim, geçerlilik ve test süreçlerini de içeren regresyon eğrileri sırasıyla Şekil 5 ve Şekil 6'da gösterilmektedir. Bahsedilen bu iki melez modelin rüzgâr hızını sırasıyla $\% 85,02$ ve $\% 70,65$ doğrulukla tahmin ettiği görülmektedir.

Bandırma istasyonu için tekli LSTM ve tüm IMF'lerin dahil edildiği melez EMD-LSTM modelleri için elde edilen tahmin sonuçları Şekil 7'de sunulmaktadır. IMF2'nin dahil edilmediği en yüksek hataya sahip melez model ile IMF10'un dahil edilmediği en düşük hataya sahip melez model için elde edilen tahmin sonuçları Şekil 8'de verilmektedir. Ayrıca, her bir IMF'nin dahil edilmediği melez rüzgâr hızı tahmin modellerinin performansı Şekil 9 ve Şekil 10'da gösterilmektedir. Şekil 8 incelendiğinde, en yüksek hata payına sahip IMF2'nin dahil edilmediği melez modelin gerçek rüzgâr hızının anlık değişimlerini tahmin edemediği görülmektedir. Durağan olmayan rüzgâr hızının yüksek hassasiyetle tahmini için EMD’nin IMF2 değerinin kritik öneme sahip olduğu değerlendirilmektedir. Çalışmada kullanılan her bir model için Tablo 1'de verilen sonuçlarla birlikte Şekil 5, Şekil 6 ve Şekil 8 birlikte değerlendirildiğinde, hesaplama karmaşıklığının azaltılması gerektiği durumlarda, IMF10'un dahil edilmediği melez tahmin modelinin tüm IMF'lerin dahil edildiği melez modele alternatif olarak yaklaşık $\% 5$ hata ile kullanılabileceği görülmektedir.

e-ISSN: 2148-2683
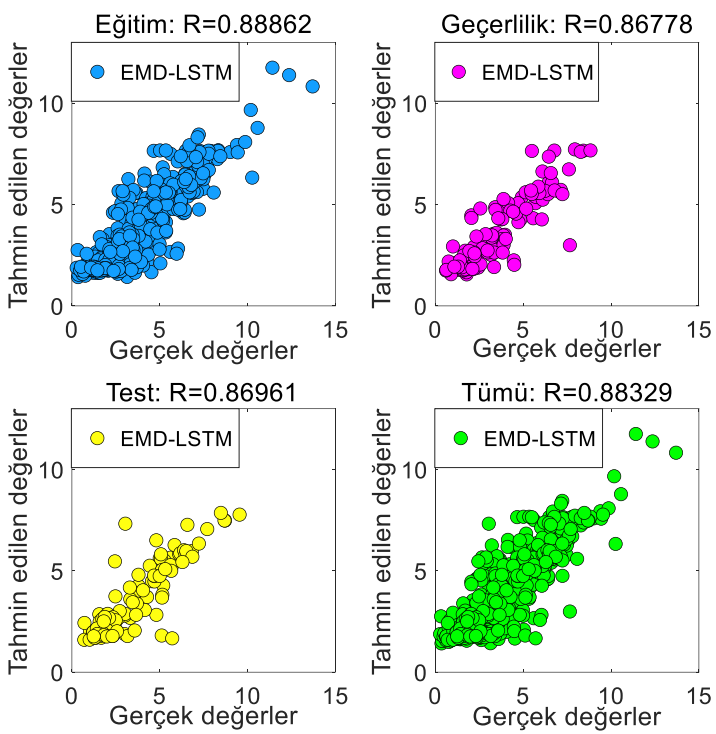

Şekil 4. EMD-LSTM tahmin modeli için regresyon ĕ̆risi.
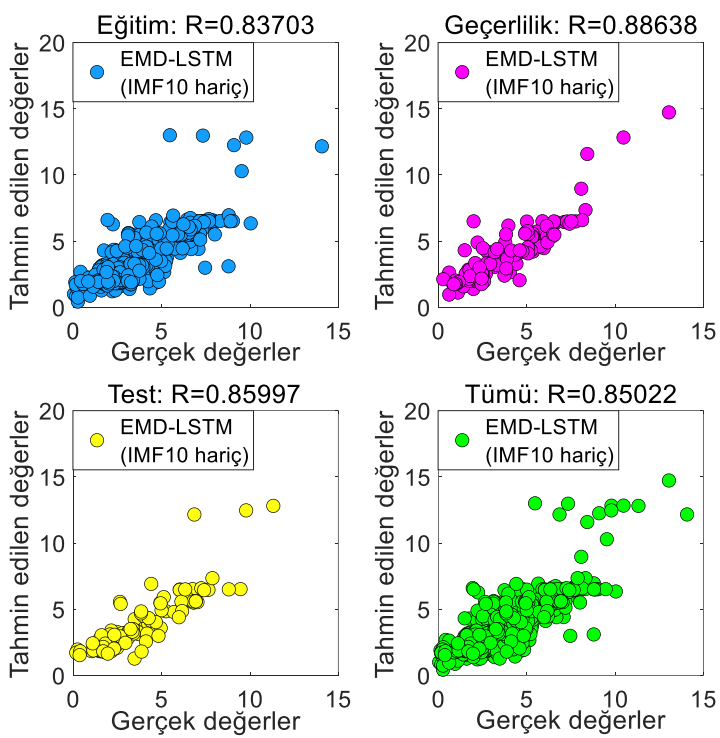

Şekil 5. EMD-LSTM (IMF 10 hariç) tahmin modeli için regresyon eğrisi.
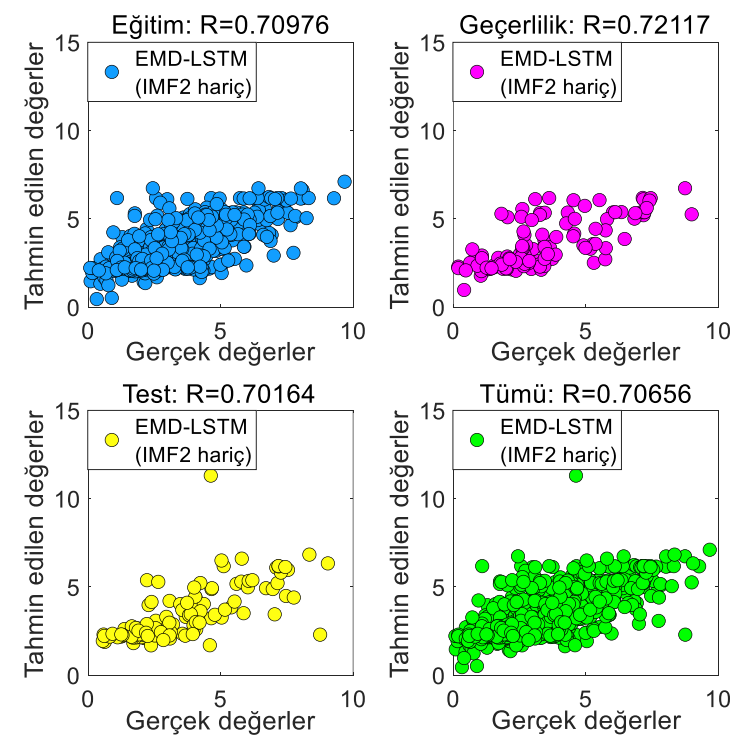

Şekil 6. EMD-LSTM (IMF 2 hariç) tahmin modeli için regresyon ĕgrisi. 


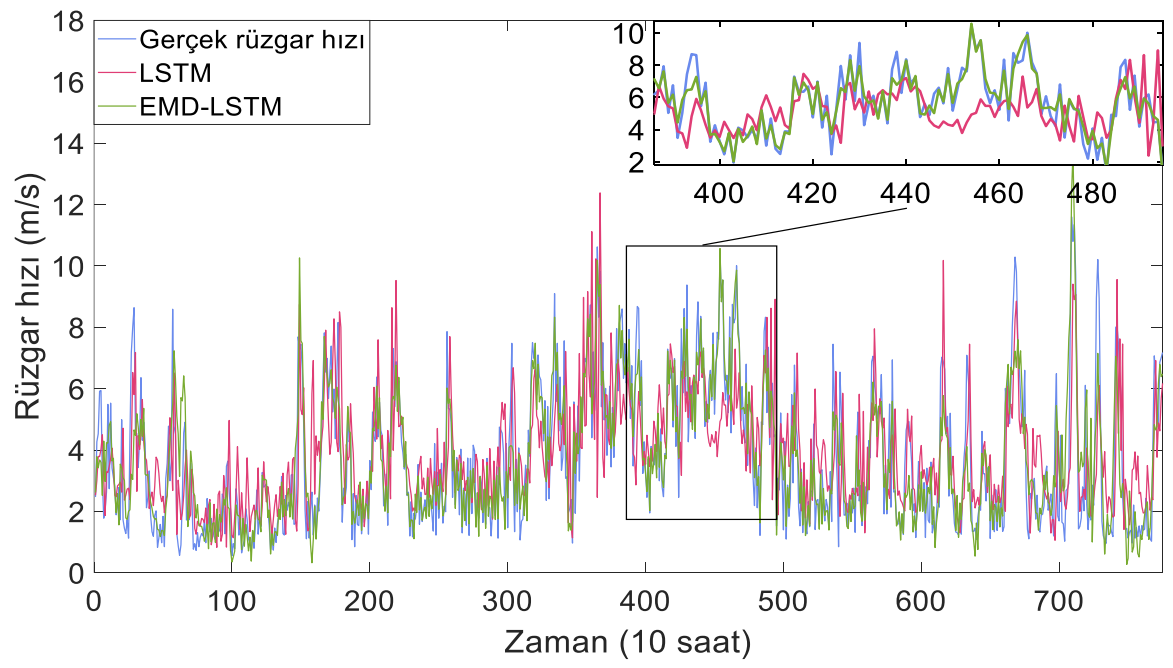

Şekil 7. Bandırma istasyonu için LSTM ve EMD-LSTM modellerinin rüzgâr hızı tahmin performansı.

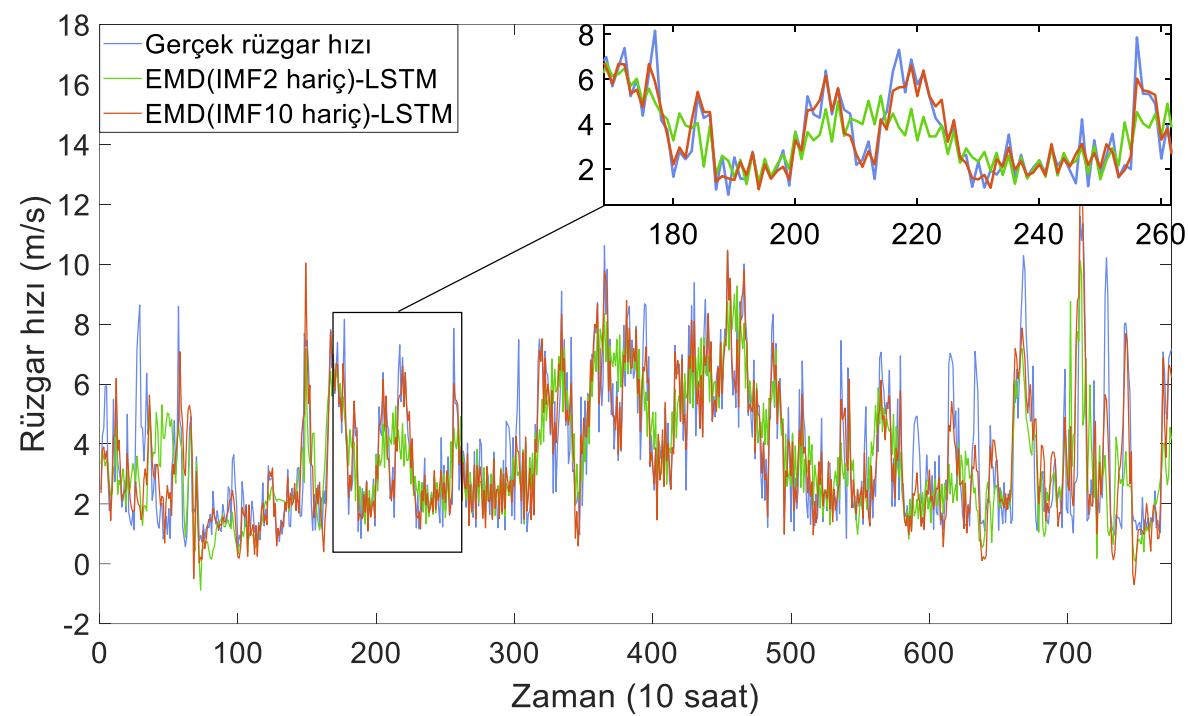

Şekil 8. Bandırma istasyonu için EMD-LSTM (IMF 2 hariç) ve EMD-LSTM (IMF 10 hariç) modellerinin rüzgâr hızı tahmin performansl.

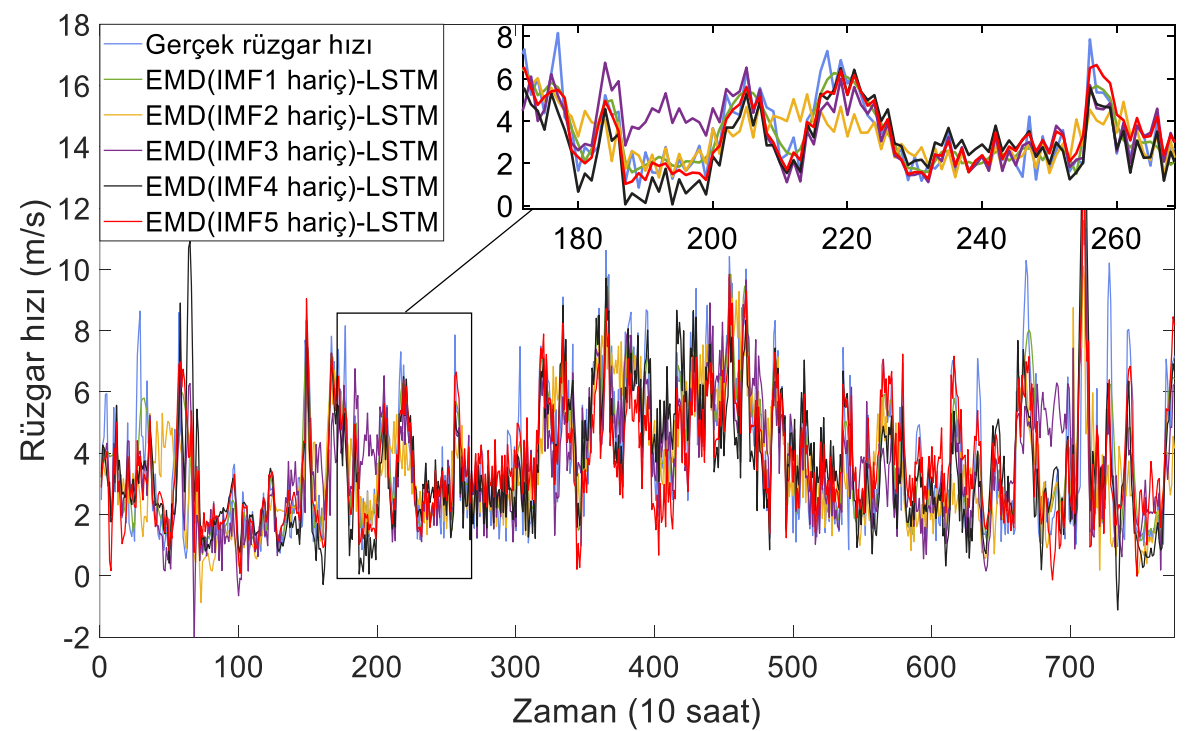

Şekil 9. Bandırma istasyonu için IMF 1-5 hariç tutulduğu EMD-LSTM modellerinin rüzgâr hızı tahmin performansı. 


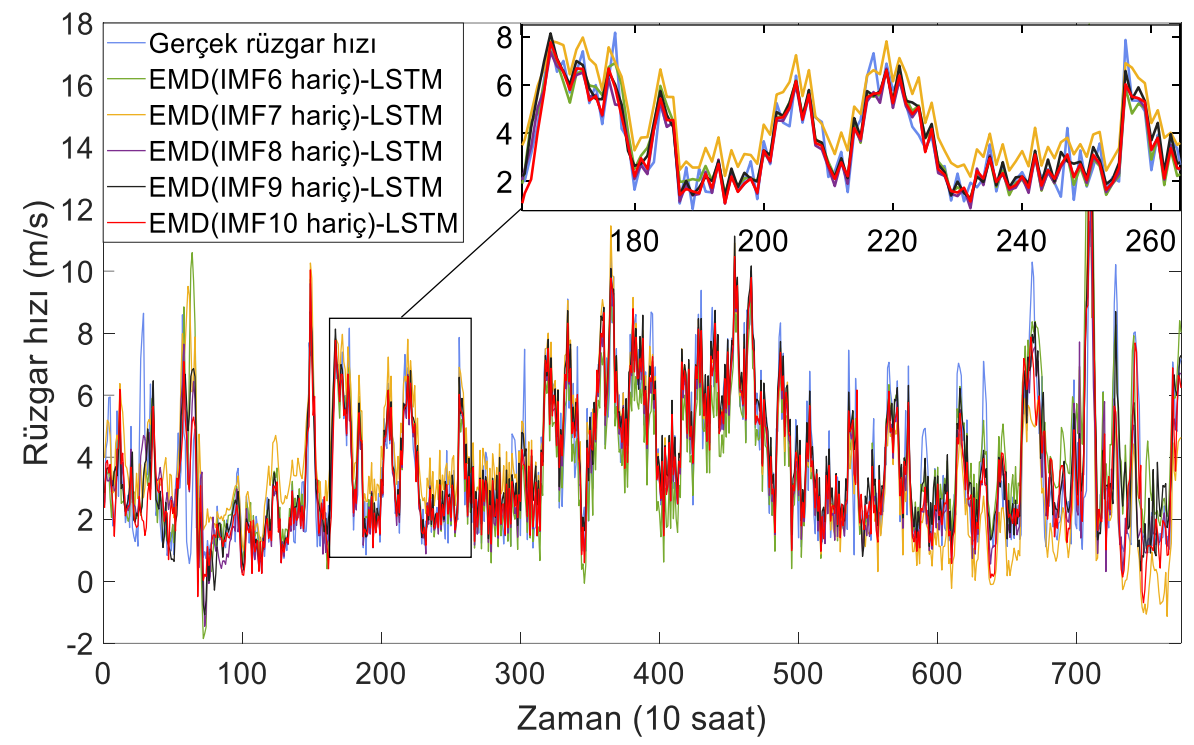

Şekil 10. Bandırma istasyonu için IMF 6-10 hariç tutulduğu EMD-LSTM modellerinin rüzgâr hızı tahmin performansı.

\section{Sonuçlar ve Gelecekteki Çalışmalar}

Son y1llarda etkisini artarak hissettiren iklim değişikliği ile mücadelede önemi daha da ön plana çıkan ve temiz bir enerji kaynağı olan rüzgâr gücünün elektrik şebekesine entegre edilerek rüzgâr enerjisinden etkin şekilde faydalanılabilmesi için rüzgâr hızının güvenilir ve yüksek hassasiyetle tahmini hayati önem taşımaktadır. Derin öğrenme tabanlı tekli modellerin kısa vadeli rüzgâr hızı tahmininde gösterdiği performansın sınırlı olduğu görülmektedir. Rüzgâr hızı zaman serilerindeki doğrusal olmayan dinamikler ile baş etmede sinyal ayrıştırma yöntemleri etkili olmakta ve oluşturulan melez tahmin modelinin performansını iyileştirmektedir. Bununla birlikte, kullanılan ayrıştırma teknikleri tahmin modelinin hesaplama karmaşıklığını artırmaktadır. Güvenilir ve yüksek doğrulukla rüzgâr hızı tahmininde oluşturulan modelin hesaplama karmaşıklığının en aza indirilmesi rüzgâr gücünün elektrik şebekesine entegre edilebilmesine imkân tanımaktadır. Bu çalışmada, sinyal ayrıştırma tekniklerini içeren derin öğrenme tabanlı melez tahmin modellerinin hem hesaplama karmaşıklığının en aza indirilebilmesi hem de yüksek doğrulukla rüzgâr hızının tahmin edilebilmesi için ayrıştırma yöntemi ile elde edilen her bir IMF'nin tahmin performansı üzerine etkisi araştırılmıştır. Elde edilen sonuçlar tekli LSTM ve melez EMD-LSTM modellerinin tahmin performansları ile kıyaslanmıştır. EMD tekniği ile elde edilen IMF'lerin her birinin tahmin performansı üzerindeki etkilerinin belirlenebilmesi için her bir IMF'nin dahil edilmediği melez rüzgâr hızı modellerin tahmin performansları hata metriklerine göre ölçülmüştür. Deneysel sonuçlar incelendiğinde, EMD'nin 2'nci IMF'sinin hariç tutulduğu melez modelin en düşük, 10'uncu IMF'sinin hariç tutulduğu melez modelin ise diğer IMF'lerin dahil edilmediği durumlara göre en yüksek tahmin performasına sahip olduğu gözlemlenmiştir. Deneysel sonuçlar, melez rüzgâr hızı tahmin modellerinin performansının belirli bir tolerans aralığında tutularak modelin hesaplama karmaşıklığının azaltılabileceğini ortaya koymaktadır. Gelecek çalışmalarda, her bir IMF'nin diğer IMF'ler ile kombine olduğu durumlar dikkate alınarak birden fazla IMF'nin dahil edilmediği melez rüzgâr hızı tahmin modellerinin performansları incelenecektir. En az hesaplama karmaşıklığ 1 ile birlikte en yüksek tahmin performansına sahip rüzgâr hızı tahmin modellerinin herhangi bir optimizasyon algoritmasına gerek kalmadan elde edilebilmesine ve elde edilen tahmin modelinin uygulanabilir olmasına olanak sağlanacaktır.

\section{Kaynakça}

Akçay, H. \& Filik, T. (2017). Short-term wind speed forecasting by spectral analysis from long-term observations with missing values. Applied Energy, 191, 653-662.

Altan, A. \& Karasu, S. (2021). Ayrıştırma yöntemlerinin derin öğrenme algoritması ile tanımlanan rüzgâr hızı tahmin modeli başarımına etkisinin incelenmesi. Avrupa Bilim ve Teknoloji Dergisi, 20, 844-853.

Altan, A., Karasu, S., \& Zio, E. (2021). A new hybrid model for wind speed forecasting combining long short-term memory neural network, decomposition methods and grey wolf optimizer. Applied Soft Computing, 100, 106996.

Cadenas, E., Rivera, W., Campos-Amezcua, R., \& Heard, C. (2016). Wind speed prediction using a univariate ARIMA model and a multivariate NARX model. Energies, 9(2), 109.

Chen, C. F., Lai, M. C., \& Yeh, C. C. (2012). Forecasting tourism demand based on empirical mode decomposition and neural network. Knowledge-Based Systems, 26, 281-287.

Chen, Y., Dong, Z., Wang, Y., Su, J., Han, Z., Zhou, D., Zhang, K., Zhao, Y., \& Bao, Y. (2021). Short-term wind speed predicting framework based on EEMD-GA-LSTM method under large scaled wind history. Energy Conversion and Management, 227, 113559.

Chen, Y., He, Z., Shang, Z., Li, C., Li, L., \& Xu, M. (2019). A novel combined model based on echo state network form multi-step ahead wind speed forecasting: A case study of NREL. Energy Conversion and Management, 179, 13-29.

Gauterin, E., Kammerer, P., Kühn, M., \& Schulte, H. (2016). Effective wind speed estimation: comparison between Kalman filter and Takagi-Sugeno observer techniques. ISA Transactions, 62, 60-72.

Hochreiter, S. \& Schmidhuber, J. (1997). Long short-term memory, neural computation, 9(8), 1735-1780.

Hoolohan, V., Tomlin, A. S., \& Cockerill, T. (2018). Improved near surface wind speed predictions using Gaussian process regression combined with numerical weather predictions and 
observed meteorological data. Renewable Energy, 126, 10431054.

Huang, N. E., Shen, Z., Long, S. R., Wu, M. C., Shih, H. H., Zheng, Q., Yen, N. C, Tung, C. C., \& Liu, H. H. (1998). The empirical mode decomposition and the Hilbert spectrum for nonlinear and non-stationary time series analysis. Proceedings of the Royal Society of London, Series A: Mathematical, Physical and Engineering Sciences, 454(1971), 903-995.

Huang, N. E., Wu, M. L. C., Long, S. R., Shen, S. S., Qu, W., Gloersen, P., \& Fan, K. L. (2003). A confidence limit for the empirical mode decomposition and Hilbert spectral analysis. Proceedings of the Royal Society of London. Series A: Mathematical, Physical and Engineering Sciences, 459(2037), 2317-2345.

Karasu, S., Altan, A., Saraç, Z., \& Hacıŏlu, R. (2017a). Estimation of fast varied wind speed based on NARX neural network by using curve fitting. International Journal of Energy Applications and Technologies, 4(3), 137-146.

Karasu, S., Altan, A., Saraç, Z., \& Hacioğlu, R. (2017b). Prediction of wind speed with non-linear autoregressive (NAR) neural networks. IEEE 25th Signal Processing and Communications Applications Conference, Antalya-Turkey.

Liu, H. \& Chen, C. (2019). Data processing strategies in wind energy forecasting models and applications: a comprehensive review. Applied Energy, 249, 392-408.

Liu, H., Duan, Z., Wu, H., Li, Y., \& Dong, S. (2019). Wind speed forecasting models based on data decomposition, feature selection and group method of data handling network. Measurement, 148, 106971.

Liu, H., Tian, H. Q., \& Li, Y. F. (2012). Comparison of two new ARIMA-ANN and ARIMA-Kalman hybrid methods for wind speed prediction. Applied Energy, 98, 415-424.

Liu, X., Lin, Z., \& Feng, Z. (2021). Short-term offshore wind speed forecast by seasonal ARIMA-A comparison against GRU and LSTM. Energy, 227, 120492.

Ma, X., Jin, Y., \& Dong, Q. (2017). A generalized dynamic fuzzy neural network based on singular spectrum analysis optimized by brain storm optimization for short-term wind speed forecasting. Applied Soft Computing, 54, 296-312.

Ma, Z., Chen, H., Wang, J., Yang, X., Yan, R., Jia, J., \& Xu, W. (2020). Application of hybrid model based on double decomposition, error correction and deep learning in shortterm wind speed prediction. Energy Conversion and Management, 205, 112345.

Ruiz-Aguilar, J. J., Turias, I., González-Enrique, J., Urda, D., \& Elizondo, D. (2021). A permutation entropy-based EMDANN forecasting ensemble approach for wind speed prediction. Neural Computing and Applications, 33(7), 23692391.

Sainath, T. N., Vinyals, O., Senior, A., and Sak, H. (2015). Convolutional, long short-term memory, fully connected deep neural networks. IEEE International Conference on Acoustics, Speech and Signal Processing, BrisbaneAustralia, 4580-4584.

Statistical Review of World Energy 2021. Available from: https://www.bp.com/content/dam/bp/business-sites /en/global/corporate/pdfs/energy-economics/statistical-re view/bp-stats-review-2021-renewable-energy.pdf

U.S. Energy Information Administration. Available from: https://www.eia.gov/renewable/data.php\#wind.

Yan, X., Liu, Y., Xu, Y., \& Jia, M. (2020). Multistep forecasting for diurnal wind speed based on hybrid deep learning model with improved singular spectrum decomposition. Energy Conversion and Management, 225, 113456.

Yu, C., Li, Y., Bao, Y., Tang, H., \& Zhai, G. (2018). A novel framework for wind speed prediction based on recurrent neural networks and support vector machine. Energy Conversion and Management, 178, 137-145.

Zhang, D., Xu, Z., Li, C., Yang, R., Shahidehpour, M., Wu, Q., \& Yan, M. (2019). Economic and sustainability promises of wind energy considering the impacts of climate change and vulnerabilities to extreme conditions. The Electricity Journal, 32(6), 7-12.

Zhao, Y., Ye, L., Pinson, P., Tang, Y., \& Lu, P. (2018). Correlationconstrained and sparsity-controlled vector autoregressive model for spatio-temporal wind power forecasting. IEEE Transactions on Power Systems, 33(5), 5029-5040. 